\title{
Dynamic Equivalence of Wind Farms Considering Complex Terrain
}

\author{
Wenzhe Zheng ${ }^{1}$, Jing Bu' ${ }^{1}$, Ningyu Zhang ${ }^{2}$, Qian Zhou ${ }^{2}$ and Jiankun Liu ${ }^{2}$ \\ ${ }^{1}$ Nanjing University of Science and Technology, No.200 Xiaolingwei Road, Nanjing, China \\ ${ }^{2}$ Jiangsu Electric Power Company Research Institute, No.1 Pavel Road, Nanjing, China
}

\begin{abstract}
The dynamic equivalence of wind farms is widely used for model simplification. While, the accuracy will be lower without considering the influence of wind speed correlation caused by topography and wake effect. In order to improve the accuracy, this paper proposes a dynamic cluster equivalence method of coherent generators based on hierarchical clustering analysis. Firstly, it analyses the impacts of equivalence's accuracy such as wind speed distribution, wake effect and control strategy of turbine. Then, it uses hierarchical clustering method to correlate the disturbed trajectory of rotor current of the intra-site turbines and obtains the dynamic clustering results. Finally, it uses power loss method to obtain the equivalent parameters of multi-machine equivalent model. Simulation results verify the effectiveness of this method.
\end{abstract}

\section{Introduction}

As the scale of wind farms grows, we focus on the impact of dynamic characteristics on the system. If we use detailed model of wind farms to analyse, it will increase the amount of calculation to be "dimensional disasters" [1]. Therefore, it becomes a research hotspot to find a suitable simplified method for clustering equivalence [2].

Dynamic equivalent methods which commonly used are single-machine and multi-machine equivalence [3-4]. The single-machine equivalent method is to equalize a wind farm into a wind turbine. But due to the wake effects and wind speed distribution, merely superimposing mechanical power leads to large error for large-scale wind farms [5]. Therefore, multi-machine equivalence is obviously more suitable in the actual situation. Some scholars have proposed an equivalent method for classifying by wind speed [6] of turbines. However, due to the difference of the control method of turbines caused by complex terrain, there is a certain difference between the dynamic characteristics of turbines in a large-scale wind farm. Consequently, it is necessary to consider the impact of the complex terrain on the clustering of the wind turbines. Many studies are focus on the dynamic coherence characteristics of wind turbines. For instance, references [7-9] research the division of the coherent turbines composed of doubly fed induction generators (DFIG). It uses the transient trajectory of the turbines' voltage or rotor current to cluster. When turbines are regular arranged without complex terrain, traditional method is suitable. But the actual different spatial position is ignored.

Thus, this paper proposes a dynamic clustering equivalent method that takes into account the intra-site complex terrain. In a wind farm with complex terrain, turbines with similar geographical locations are on a collection line [10]. Firstly, turbines are clustering into several clusters according to the rotor current disturbance curve under dynamic condition. After that, the impedances of equivalent machines are researched. Finally, the accuracy of the model is verified by the simulation of MATLAB/Simulink.

\section{Influence of complex terrain}

Large-scale wind farms are often located in mountain areas, the arrangement of intra-site turbines is not a simple parallel arrangement of rows and columns. The environment factors (slope, terrain relief, ground roughness, obstacles, etc.) change the dynamic output characteristics of the wind farm. Since traditional method makes them become equivalent to one turbine, it will cause a large error in the dynamic process.

\subsection{Analysis of Wind Speed Distribution}

We will discuss the impact of wind distribution under complex terrain. According to the actual wind resource data of a wind farm throughout the year, we divide the wind direction from $0^{\circ}$ to $360^{\circ}$ evenly into 16 directions. We establish a wind resource database and get the statistics as shown in Fig. 1. Theoretically speaking, the statistical law of it is close to Weibull distribution [2]. Its probability density function and distribution function are as follows:

$$
\begin{gathered}
f(v)=(k / c)(v / c)^{k-1} \exp \left(-(v / c)^{k}\right) \\
F(v)=1-\exp \left(-(v / c)^{k}\right)
\end{gathered}
$$




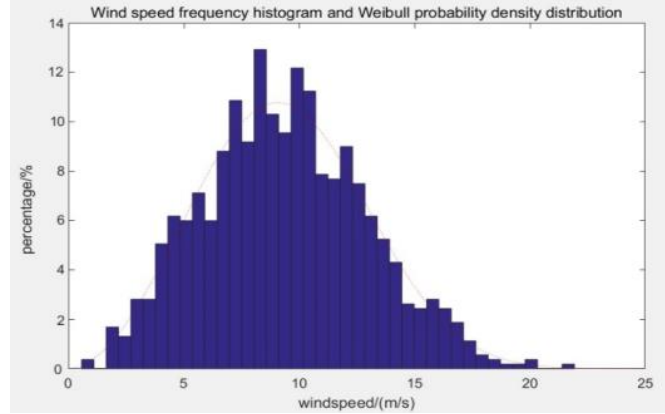

(a) Probability of Wind speed statistics

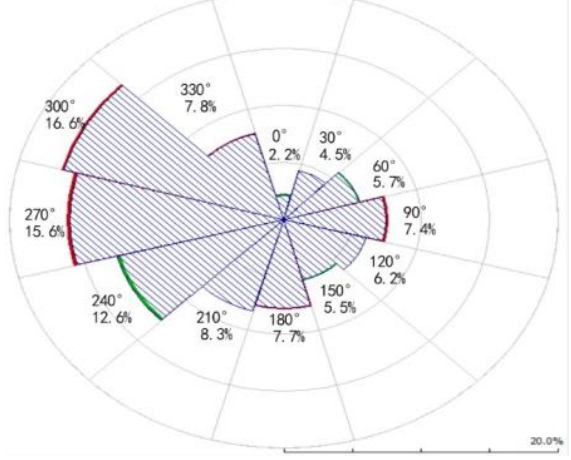

(b)Probability of Wind direction statistics

Figure 1. Wind resource statistics.

Where, $v$ represents the wind speed, $k$ and $c$ represent the shape and scale parameter of Weibull distribution.

Actually, the description of wind speed are nonlinear equations composed of the interaction of momentum, energy and mass. If the same wind speed is used as the wind farm equivalence, a large error will occur.

\subsection{Analysis of Wake effect}

Wind turbines are irregular distributed. In the upwind position, the turbine absorbs part of wind energy and forms a wake region [4]. That is wake effect, which has a certain shelter effect on the downwind turbine. Traditional equivalent methods seldom consider wake effects on input wind speed. Here we get Jensen Linear model of wake effect as shown in Fig. 2.

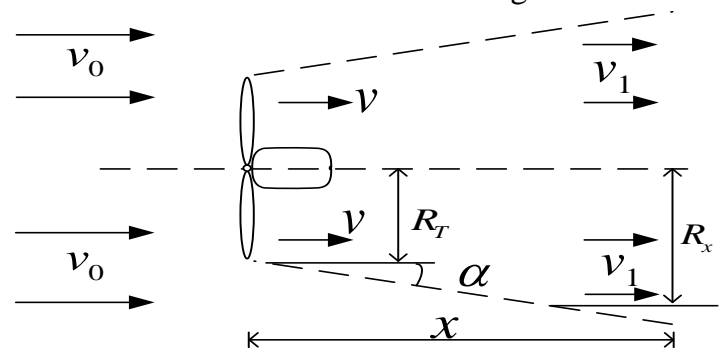

Figure 2. Linear model of wake effect.

Where, $v_{0}$ is the input wind speed of upwind turbine, while $v$ is under wake effect. $R_{T}$ is the blade radius of turbines, $R x$ and $v_{l}$ represent the wake radius and input wind speed that is away from upwind turbine at the distance of $x$. Therefore, input wind speed of downwind turbine can be expressed as:

$$
\begin{aligned}
& v_{1}=v_{0}\left[1-\left(R_{T} / R_{x}\right)^{2}\left(1-\sqrt{1-C_{T}}\right)\right] \\
& R_{x}=R_{T}+x \cdot \tan \alpha
\end{aligned}
$$

Where, $\alpha$ means the wake attenuation constant and $C_{T}$ is the thrust coefficient of turbines. Considering the influence of complex terrain, wind turbines are often irregularly arranged. There is no doubt that wake effect will increase. A wind turbine may be affected by more than one turbine. Taking this into account, we obtain the equation of wind speed as:

$$
\begin{aligned}
v_{j}\left(x_{i j}, h_{j}\right)= & v_{i}\left[1-\left(1-\sqrt{1-C_{T}}\right)\left(h_{i} / h_{j}\right)^{2 \alpha}\right. \\
& \left.\cdot\left(R_{j} / R_{i}\left(x_{i j}\right)\right)^{2}\left(A_{\text {shadow }, i j} / A_{\text {rotor }}\right)\right]\left(h_{j} / h_{i}\right)^{\alpha}
\end{aligned}
$$

Where, $i$ and $j$ stand for upwind and downwind turbines respectively, and the horizontal distance of them is $x_{i j}$. Besides, $h_{i}$ and $h_{j}$ respectively indicate the altitude of turbines. $R_{j}$ is the blade radius of the downwind turbine, and $R_{j}\left(x_{i j}\right)$ represents the radius under wake effect of upwind turbine at the position of it, which can be obtained by (1). And $A_{\text {rotor }}=\pi R_{j}^{2}$, it means the blade sweep area. $A_{\text {shadow, } i j}$ is the overlap area under wake effect, expressed as:

$$
\begin{aligned}
& A_{\text {shadow }, i j}=R_{i}^{2}\left(x_{i j}\right) \arccos \left(\frac{R_{i}^{2}\left(x_{i j}\right)+d_{i j}^{2}+\Delta h^{2}-R_{j}^{2}}{2 R_{i}\left(x_{i j}\right) \sqrt{\Delta h^{2}+d_{i j}^{2}}}\right)+ \\
& R_{j}^{2} \arccos \left(\frac{R_{j}^{2}+d_{i j}^{2}+\Delta h^{2}-R_{i}^{2}\left(x_{i j}\right)}{2 R_{j} \sqrt{\Delta h^{2}+d_{i j}^{2}}}\right)-R_{i}\left(x_{i j}\right) \sqrt{\Delta h^{2}+d_{i j}^{2}} \cdot(5 \\
& \sin \left(\arccos \left(\frac{R_{i}^{2}\left(x_{i j}\right)+d_{i j}^{2}+\Delta h^{2}-r_{j}^{2}}{2 R_{i}\left(x_{i j}\right) \sqrt{\Delta h^{2}+d_{i j}^{2}}}\right)\right) \\
& )
\end{aligned}
$$

Where, $d_{i j}$ means the distance between the horizontal axis of upwind and downwind turbine, and $\Delta h=\left|h_{i}-h_{j}\right|$ is their difference in altitude. The whole model is shown in Fig.3.

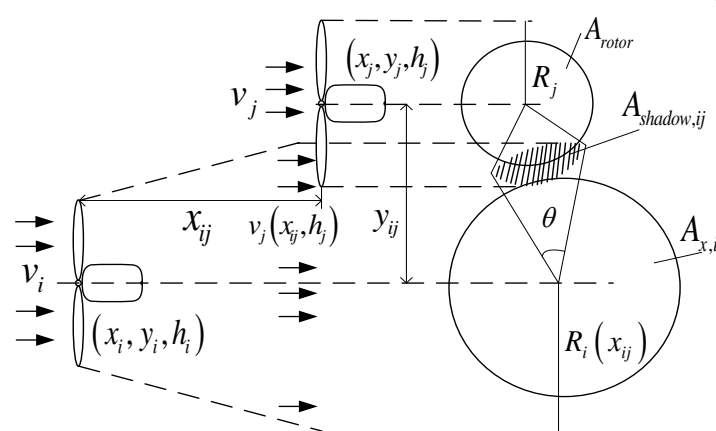

Figure 3. Partial block model model of wake effect.

\subsection{Analysis of surface roughness and obstacle}

When air flows close to the surface, resistance due to friction on the ground and obstacle cause loss of energy. That can affect wind speed. As the height increases, the influence of surface roughness decreases. In addition, the roughness of different terrains affects the wind speed. Due to the presence of roughness, the wind speed changes with height as follows:

$$
\frac{v}{v_{0}}=\frac{\ln (H-d)-\ln z_{0}}{\ln \left(H_{0}-d\right)-\ln z_{0}}
$$

Where, $v$ and $v_{0}$ is the wind speed at height $H$ and $H_{0}, z_{0}$ is the roughness constant and $d$ is the obstacle 
obstruction coefficient which equals 0 if the surface obstacles are relatively fragmented.

For description of surface roughness and obstacle, it can be assigned by the software WAsP. Common surface roughness values are in Table 1.

Table 1. Roughness of common surface types

\begin{tabular}{|l|l|}
\hline Surface types & $z_{0}(\mathbf{m})$ \\
\hline City、 forest & 0.7 \\
\hline Suburb、 rural area & 0.3 \\
\hline Villages with trees & 0.1 \\
\hline Open pasture with few trees or houses & 0.03 \\
\hline Flat grass & 0.01 \\
\hline Desert and sea surface & 0.001 \\
\hline
\end{tabular}

\subsection{Analysis of turbines under different control methods}

In actual wind farm with complex terrain, turbines with different position receive different wind speeds. Their operating conditions are also different. Thus, an actual wind farm often adopts different control methods on turbines. Under different control methods, the dynamic characteristics of wind turbines are different. DFIGs usually adopt constant power factor and constant voltage control. In order to further analyze it, we simulate the wind turbine grid-connected model in MATLAB. The input wind speed is $10 \mathrm{~m} / \mathrm{s}$. The three-phase fault occurs at the point of integration and lasts $0.15 \mathrm{~s}$. Wind turbines use constant voltage control and constant power factor control, respectively. Here is the result of disturbed curves under different control methods as shown in Fig.4.

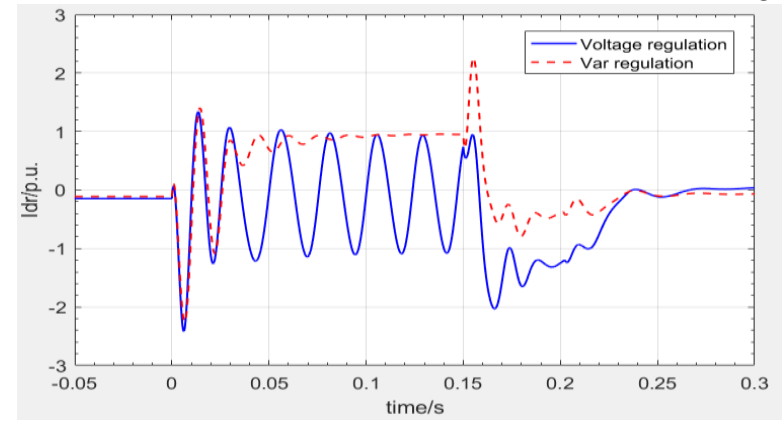

(a)The rotor d-axis current

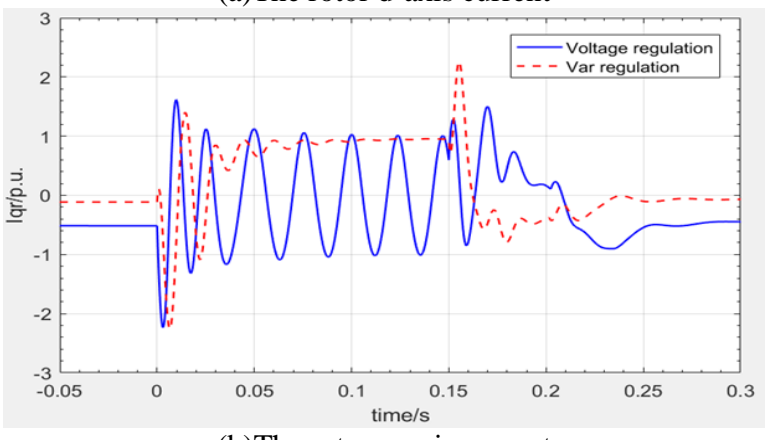

(b)The rotor q-axis current

Figure 4. Disturbed curves under different control strategy.

Obviously, different control methods for turbines have a great influence on the rotor current disturbed curves. As a result, the dynamic clustering equivalence of wind farms will be affected.

\section{Dynamic clustering method of wind farm considering complex terrain}

\subsection{Coherent Basis of Wind Turbines}

For dynamic equivalence of wind farms, clustering analysis is a key step to get equivalent parameters. Traditional clustering strategy only analyzes characteristics of a single turbine. However, this will cause deviations from clustering if considering complex terrain. Thus, this paper calculates the whole dynamic process (before and after the fault) of wind turbines considering irregular arrangement at complex terrain. According to the method proposed in [10], the disturbed trajectory of rotor current can be the coherent evaluation indicator. So, we use the similarity of it to effectively identify the differences of turbines in dynamic processes. Therefore, we obtain the clustering basis considering complex terrain.

\subsection{Dynamic Clustering Method}

Shown from above, clustering algorithms can be used to group wind turbines with a wind farm. This paper will use hierarchical clustering algorithm for clustering. It is because that there is no need to specify the number of clusters in advance. As an iterative optimization process, the objective function of clustering algorithm usually uses distance as evaluation criteria. According to the coherence basis, this paper clusters the correlation coefficients of dynamic characteristics of rotor current for each turbine. The specific process is as follows:

1) Collect the complete dynamic track of each turbine's rotor current during a certain period of time using the offline data of the wind farm.

2) Calculate the correlation coefficient for each group of rotor current trajectories according to the principle of coherence discrimination. It is defined as follows:

$$
\begin{aligned}
C_{i j}=\frac{\sum_{k=1}^{n}\left(x_{k i}-\bar{x}_{i}\right)\left(x_{k j}-\bar{x}_{j}\right)}{\sqrt{\left[\sum_{k=1}^{n}\left(x_{k i}-\bar{x}_{i}\right)^{2}\right]\left[\sum_{k=1}^{n}\left(x_{k j}-\bar{x}_{j}\right)^{2}\right]}} \quad \begin{array}{l}
i=1,2, \cdots, p \\
j=1,2, \cdots, \mathrm{p}
\end{array} \\
\bar{x}_{i}=\frac{1}{n} \sum_{k=1}^{n} x_{k i} \bar{x}_{j}=\frac{1}{n} \sum_{k=1}^{n} x_{k j}
\end{aligned}
$$

Where, the distance between variables $x_{i}$ and $x_{j}$ can also be defined by correlation coefficient.

3) Start hierarchical clustering. Initially, all the current variables of each turbine are sampled into different clusters, and the distance between the groups are defined as follows:

$$
d_{i j}=1-C_{i j}, \begin{aligned}
& i=1,2, \cdots, p \\
& j=1,2, \cdots, p
\end{aligned}
$$

4) Combine the two nearest clusters into a new cluster, calculate the distance with others, and repeat the merger. Each time reduce a group until the current variables of all turbines merge into one cluster. A clustering tree is finally formed. It is usually clear from the figure that there should be several clusters and the DFIGs included in each cluster. In hierarchical clustering, the cluster is 
represented by $G$. Assume that there are $m$ turbines ( $m$ groups of current vectors) in $G$, represented by the column vector $x_{i}(i=1,2, \ldots, m), d_{i j}$ represents the distance between vector $x_{i}$ and $x_{j}$, and $D_{K L}$ represents the distance between cluster $G_{K}$ and $G_{L}$. This paper considers the complete trajectory of the current vector. Therefore, the Class Average Method is used to define the average of the squared distances between sampling points at each time. Thus, the squared distance between $G_{K}$ and $G_{L}$ is as follows:

$$
D_{K L}^{2}=\frac{1}{n_{K} n_{L}} \sum_{x_{i} \in G_{K}} d_{i j}^{2}
$$

The squared distance between clusters is as follows:

$$
D_{M J}^{2}=\frac{n_{K}}{n_{M}} D_{K J}^{2}+\frac{n_{L}}{n_{M}} D_{L J}^{2}
$$

By increasing $D_{K L}{ }^{2}$ and generalizing the above formula, the recurrence formula for the squared distance between clusters can be obtained as follows:

$$
D_{M J}^{2}=(1-\beta)\left[\frac{n_{K}}{n_{M}} D_{K J}^{2}+\frac{n_{L}}{n_{M}} D_{L J}^{2}\right]+\beta D_{K L}^{2}
$$

Where, $\beta<1$. It can be called Variable Class Average Method.

\subsection{Calculation of Equivalent Parameters}

1) Wind speed equivalence

Assume that all wind turbines work at the state of maximum power point tracking (MPPT), the speed of equivalent machine can be obtained as follows:

$$
\omega_{e q}=\sum_{i=1}^{n} P_{m i} / \sum_{i=1}^{n} T_{m i}
$$

Where, $n$ is the number of turbines in the cluster, $P_{i}$ and $T_{m i}$ are the mechanical power and torque of the $i$-th turbine.

The radius of the rotor of the equivalence is as follows:

$$
R_{e q}=\frac{1}{n} \sum_{i=1}^{n} R_{i}
$$

Where, $R_{i}$ represents the radius of the rotor of the $i$-th turbine.

Its tip speed ratio is as follows:

$$
\lambda_{e q}=\frac{\omega_{e q} R_{e q}}{v_{e q}}
$$

Where, $v_{e q}$ is input wind speed of the equivalent turbine. The expression of its mechanical power is as follows:

$$
P_{m e q}=\sum_{i=1}^{n} P_{m i}=\frac{1}{2} \rho \pi R_{e q}^{2} C_{p}\left(\lambda_{e q}, \beta_{e q}\right) v_{e q}^{3} \cdot n
$$

Where, $\rho$ represents air density which is usually $1.229 \mathrm{~kg} / \mathrm{m}^{3}, \beta_{e q}$ represents equivalent pitch angle which is always zero in this case, and $C_{p}$ is the wind energy utilization factor. Then according to the above relationship, the solution of the equivalent wind velocity $v_{e q}$ can be obtained.

2) Turbine parameters and transformer equivalence
Since each turbine has the same capacity and model, the equivalent machine parameters are related to the number of turbines in the cluster. This paper uses the capacity weighting method in [10] to obtain the parameters of each component of the equivalent machine. 3) equivalence of Collection line's impedance

Using the equivalent power loss method, equivalent impedance of collection line is as follows:

$$
Z_{e q}=\frac{1}{P_{Z s}^{2}} \sum_{i=1}^{n}\left(P_{Z i}^{2} Z_{l i}\right)
$$

Where, $Z_{l i}$ is the feeder impedance of $i$-th turbine's branch, $P_{Z i}$ and $P_{Z s}$ are the power flow through $i$-th branch and the equivalent one, and $n$ is the number of turbines in the cluster.

\section{Simulation case study}

\subsection{Case Introduction}

We make the wind farm shown in Fig. 5 as an example. It consists of 4 collection lines and 16 turbines. Each turbine is connected to the collection network through a step-up transformer at the machine terminal and each group of 4 turbines is connected to a group of feeders. These 4 feeders are connected to the point of common coupling (PCC) bus and are connected to the infinity system via two step-up transformers via double loop transmission line.

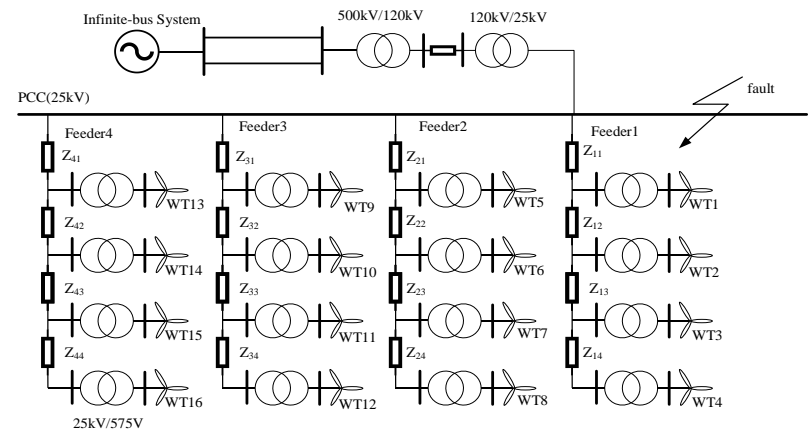

Figure 5. Diagram of the wind farm.

The location of the wind farm in the wind power management software WAsP is shown in Fig. 6. The system parameters are as follows:

All wind turbines adopt the Bonus 1.5MW DFIG model, the transformer turns into $0.575 / 25 \mathrm{kV}$, the resistance and reactance of feeder cable are $0.1253 \Omega / \mathrm{km}$ and $0.3972 \Omega / \mathrm{km}$. Assume that turbines WT1 to WT8 use constant power factor regulation, WT9 to WT16 use constant voltage regulation. The parameters of input wind speed and feeder cable length for each turbine obtained by WAsP are shown in Table 2 . 


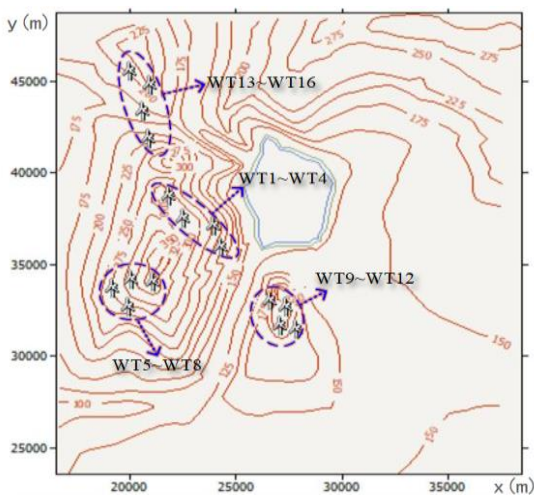

Figure 6. Wind turbine distribution map

Table 2. Site parameters of wind farm in WAsP

\begin{tabular}{|c|c|c|c|c|}
\hline Turbine & Coordinate & $\begin{array}{c}\text { Feeder } \\
\text { cable }(\mathbf{k m})\end{array}$ & $\begin{array}{c}\text { Wind } \\
\operatorname{speed}(\mathbf{m} / \mathbf{s})\end{array}$ & $\begin{array}{c}\text { Wake } \\
\operatorname{loss}(\%)\end{array}$ \\
\hline WT1 & $\begin{array}{c}(21909.6 \mathrm{~m}, \\
38329.4 \mathrm{~m}, 292.9 \mathrm{~m})\end{array}$ & $\mathrm{Z}_{11}=1.904$ & 12.0 & 0.27 \\
\hline WT2 & $\begin{array}{c}(22582.1 \mathrm{~m}, \\
37068.6 \mathrm{~m}, 289.6 \mathrm{~m})\end{array}$ & $\mathrm{Z}_{12}=1.429$ & 11.3 & 0.45 \\
\hline WT3 & $\begin{array}{c}(24011.1 \mathrm{~m}, \\
36648.3 \mathrm{~m}, 238.1 \mathrm{~m}) \\
\end{array}$ & $\mathrm{Z}_{13}=1.490$ & 10.1 & 0.86 \\
\hline WT4 & $\begin{array}{c}(24394.7 \mathrm{~m} \\
35522.1 \mathrm{~m}, 187.7 \mathrm{~m})\end{array}$ & $\mathrm{Z}_{14}=1.191$ & 10.9 & 0.63 \\
\hline WT5 & $\begin{array}{c}(21156.8 \mathrm{~m}, \\
33637.2 \mathrm{~m}, 337.2 \mathrm{~m}) \\
\end{array}$ & $\mathrm{Z}_{21}=4.141$ & 12.6 & 0.98 \\
\hline WT6 & $\begin{array}{c}(20141.9 \mathrm{~m}, \\
33733.8 \mathrm{~m}, 313.4 \mathrm{~m})\end{array}$ & $\mathrm{Z}_{22}=1.020$ & 12.3 & 0.81 \\
\hline WT7 & $\begin{array}{c}(19272.0 \mathrm{~m}, \\
33298.8 \mathrm{~m}, 275.8 \mathrm{~m})\end{array}$ & $\mathrm{Z}_{23}=0.973$ & 11.0 & 0.35 \\
\hline WT8 & $\begin{array}{c}(20045.3 \mathrm{~m}, \\
32283.9 \mathrm{~m}, 251.6 \mathrm{~m}) \\
\end{array}$ & $\mathrm{Z}_{24}=1.276$ & 10.8 & 0.35 \\
\hline WT9 & $\begin{array}{c}(26666.1 \mathrm{~m}, \\
32573.9 \mathrm{~m}, 208.9 \mathrm{~m})\end{array}$ & $\mathrm{Z}_{31}=8.273$ & 9.8 & 0.58 \\
\hline WT10 & $\begin{array}{c}(27439.3 \mathrm{~m}, \\
32235.6 \mathrm{~m}, 211.3 \mathrm{~m})\end{array}$ & $\mathrm{Z}_{32}=0.844$ & 8.6 & 1.32 \\
\hline WT11 & $\begin{array}{c}(27197.7 \mathrm{~m}, \\
31220.6 \mathrm{~m}, 204.6 \mathrm{~m})\end{array}$ & $\mathrm{Z}_{33}=1.043$ & 8.5 & 0.61 \\
\hline WT12 & $\begin{array}{c}(27922.6 \mathrm{~m}, \\
31027.3 \mathrm{~m}, 187.4 \mathrm{~m})\end{array}$ & $\mathrm{Z}_{34}=0.750$ & 9.4 & 1.31 \\
\hline WT13 & $\begin{array}{c}(20963.5 \mathrm{~m}, \\
41466.8 \mathrm{~m}, 234.1 \mathrm{~m}) \\
\end{array}$ & $\mathrm{Z}_{41}=3.908$ & 12.7 & 0.11 \\
\hline WT14 & $\begin{array}{c}(20673.5 \mathrm{~m}, \\
42916.7 \mathrm{~m}, 173.5 \mathrm{~m})\end{array}$ & $\mathrm{Z}_{42}=1.480$ & 10.8 & 0.27 \\
\hline WT15 & $\begin{array}{c}(21069.0 \mathrm{~m}, \\
44381.4 \mathrm{~m}, 209.8 \mathrm{~m}) \\
\end{array}$ & $\mathrm{Z}_{43}=1.518$ & 11.8 & 0.65 \\
\hline WT16 & $\begin{array}{c}(20060.3 \mathrm{~m}, \\
45137.9 \mathrm{~m}, 197.1 \mathrm{~m})\end{array}$ & $\mathrm{Z}_{44}=1.261$ & 9.8 & 0.24 \\
\hline
\end{tabular}

\subsection{Clustering Simulation}

A detailed model of this wind farm with complex terrain was established using MATLAB/Simulink based on the above parameters. A three-phase short circuit occurs at Point of Common Coupling (PCC) and clears after $0.15 \mathrm{~s}$. It shows the disturbed curves of rotor current of each wind turbine in Fig. 7. Furthermore, we obtain the complete operating characteristic data of each wind turbine. Next, we calculate the correlation coefficient matrix between the turbines and then use the correlation coefficient of the current as the coherence determination basis. We use the methods described in Section III. $B$ for hierarchical clustering to obtain the clustering results that turbines can be divided into 4 groups: \{WT1 WT4,
WT6,$\quad\{$ WT5, WT7, WT8,$\quad\{$ WT9 WT12 $\}$ and $\{\mathrm{WT} 13 \sim \mathrm{WT} 14\}$

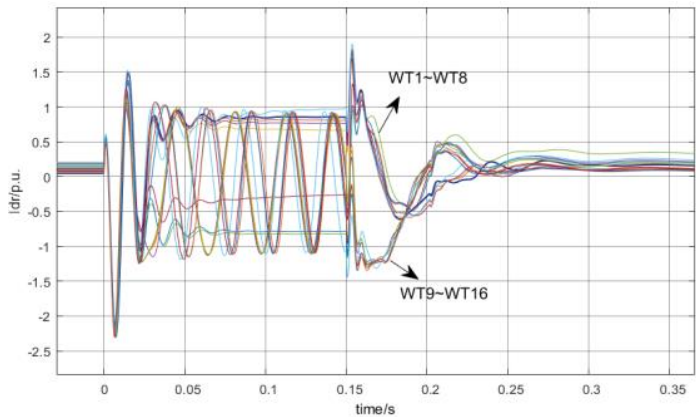

(a) The rotor current on d-axis

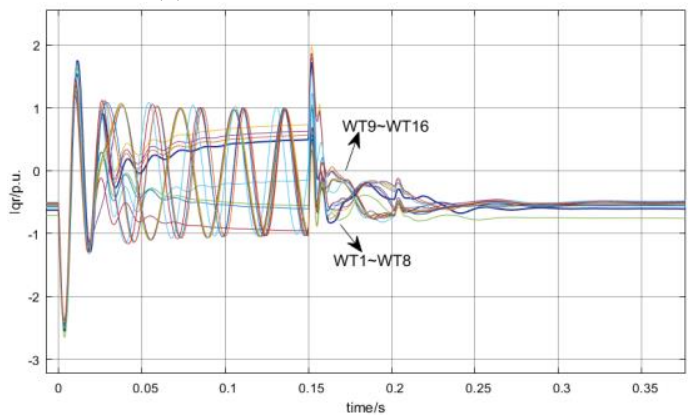

(b) The rotor current on q-axis

Figure 7. Disturbed curves of rotor current.

\subsection{Analysis of Equivalent Results}

According to the clustering result obtained in the previous section, we obtain the result of the equivalent machines as shown in Table 3.

Table 3. Wind farm's clustering and equivalent results

\begin{tabular}{|c|l|l|l|}
\hline Cluster & Turbines & $\boldsymbol{v}_{e q} /(\mathbf{m} / \mathbf{s})$ & $\boldsymbol{Z}_{e q}(\mathbf{k m})$ \\
\hline A & WT1 4, 6 & 11.3326 & 0.294 \\
\hline B & WT5,7,8 & 11.5257 & 0.967 \\
\hline C & WT9 12 & 8.9256 & 0.700 \\
\hline D & WT13 16 & 10.9957 & 0.556 \\
\hline
\end{tabular}

Based on this, the equivalent model, detailed model and traditional single-machine equivalent model are simulated and analysed respectively. And the output power dynamic curve of the wind farm is shown in Fig. 8. Taking the detailed model as a benchmark, we calculate the power average errors of the single-machine equivalent model and model of this paper as shown in Table 4

Table 4. Wind farm's clustering and equivalent results

\begin{tabular}{|c|c|c|c|}
\hline & Method & $\begin{array}{c}\text { Active } \\
\text { power/\% }\end{array}$ & $\begin{array}{c}\text { Reactive } \\
\text { power/\% }\end{array}$ \\
\hline \multirow{2}{*}{ Steady state } & Single machine method & 5.01 & 6.79 \\
\cline { 2 - 4 } & This paper & 1.61 & 2.15 \\
\hline \multirow{2}{*}{$\begin{array}{c}\text { Disturbed } \\
\text { state }\end{array}$} & Single machine method & 10.89 & 25.68 \\
\cline { 2 - 4 } & This paper & 2.89 & 10.27 \\
\hline
\end{tabular}

This paper considers the influence of complex terrain and obtain the equivalent model. Its operating status and dynamic process are basically consistent with the detailed model, and it is more accurate than the traditional singlemachine equivalent method. 


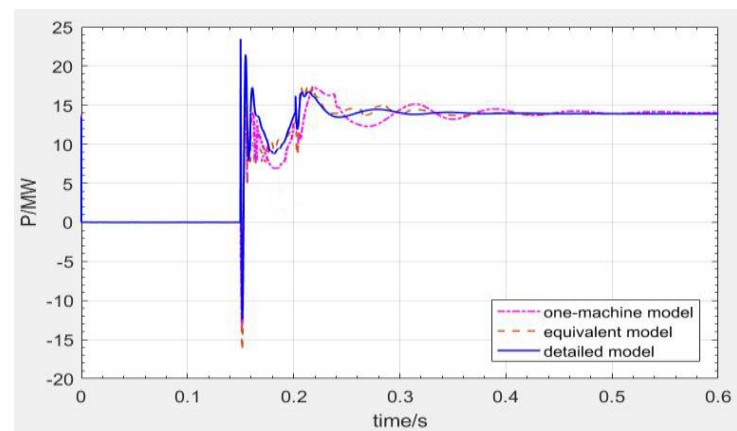

(a)Active power curve

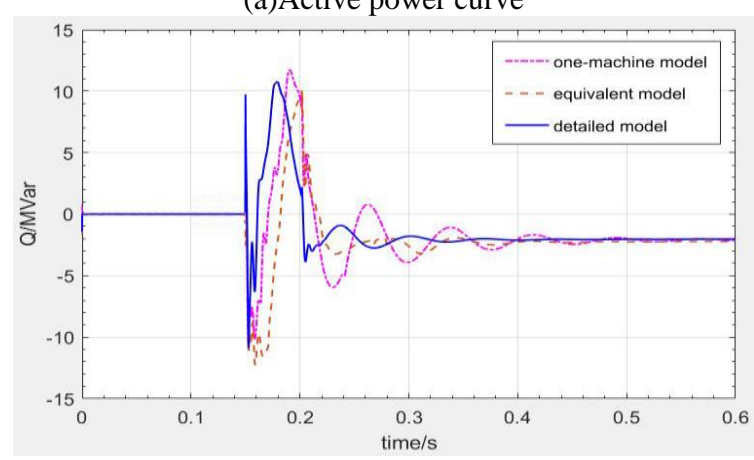

(b)Reactive power curve

Figure 8. Disturbed curves in PCC under different models.

\section{Conclusion}

This paper proposes a dynamic coherent clustering equivalent method based on the hierarchical clustering method. This method considers complex terrain while most of researchers do not concern what will influence the dynamic process of turbines, even reduce the accuracy of equivalence. Using the rotor current of turbines as the dynamic equivalent feature, the hierarchical clustering method is used to identify the coherence of the wind farm. Then the parameters equivalent method is used to obtain the dynamic equivalent parameters. Finally, the multi-machine equivalent model is obtained. Simulation results verify the effectiveness of the method.

\section{Acknowledgment}

This work was supported by the Science and Technology Project of State Grid Corporation of China (5210EF17001G).

\section{References}

[1] Y. Xu, D. Liu, Power System Protection and Control, 45(6), 108 (2017)

[2] J. Zou, C. Peng, Y. Yan, et al, Renewable \& Sustainable Energy Reviews, 40, 956 (2014)

[3] Q. Zhu, P. Han, M. Ding, et al, Proceedings of the CSEE, 34(28), 4770 (2014)

[4] J. Ge, M. Zhou, G. Li, Power System Protection and Control, 17,146 (2013)

[5] J. Ouyang, Y. Diao, D. Zheng, et al, Proceedings of the CSEE, 37(10), 2896 (2017)

[6] M A Chowdhury, W X Shen, N Hosseinzadeh, et al, Energy Conversion \& Management, 67(67), 265 (2013)

[7] H. Liu, W. Pan, P. Zhang, et al, Electric Measurement \& Instrumentation, 52(13), 31 (2015)

[8] V Akhmatov, $\mathrm{H}$ Knudsen, International Journal of Electrical Power \& Energy Systems, 24(9), 709 (2002)

[9] L M Fernández, J R Saenz, F Jurado, Renewable Energy, 31(8), 1203 (2014)

[10]X. Pan, C. Zhang, P. Ju, et al, Power System Technology, 39(3), 621 (2015) 